\title{
PERCEPÇÃO DOS EDUCANDOS DA EDUCAÇÃO PROFISSIONAL TÉCNICA SOBRE A EDUCAÇÃO AMBIENTAL: UM ESTUDO DE CASO NO IFSUL/CaVG
}

Viviane Aquino Zitzke ${ }^{1}$

Patrícia Mendes Calixto²

Resumo: $O$ artigo demonstra a abordagem da Educação Ambiental (EA) no âmbito da Educação Profissional Técnica, segundo a percepção dos educandos do Curso Técnico em Vestuário na forma de ensino integrado do IFSUL/CaVG. A Educação Ambiental investigada parte de uma visão crítica e transformadora da educação, apoiada em Loureiro (2004, 2006 e 2007) e Sauvé (2005). A pesquisa possui caráter qualitativo com dados analisados através de um questionário misto, aplicado a oito formandas. Os resultados apontaram para a prevalência da concepção conservadora da EA. A percepção do grupo estudado revelou que não há integração curricular, tampouco a transversalidade do tema EA, como determina a legislação.

Palavras-chave: Educação Ambiental Crítica e Transformadora. Educação Profissional Técnica. Ensino Médio Integrado à Educação Profissional Técnica.

\footnotetext{
1 Instituto Federal de Educação, Ciência e Tecnologia Sul-rio-grandense - campus Pelotas - Visconde da Graça. E-mail: vivianezitzke@cavg.ifsul.edu.br

2 Instituto Federal de Educação, Ciência e Tecnologia Sul-rio-grandense - campus Charqueadas. E-mail: patriciacalixto@charqueadas.ifsul.edu.br
} 


\section{Introdução}

O artigo $^{3}$ apresenta a compreensão da Educação Ambiental por meio da percepção dos educandos do curso Técnico em Vestuário, na forma de ensino integrado do Instituto Federal de Educação, Ciência e Tecnologia Sulrio-grandense (IFSUL), campus Pelotas - Visconde da Graça (CaVG), considerando as Diretrizes Curriculares Nacionais para a Educação Ambiental $(\mathrm{DCNEA})^{4}$.

O texto aborda a Educação Profissional Técnica de Nível Médio na forma Articulada e Integrada ao Ensino Médio. Esta forma de ensino é, também, denominada pela literatura como ensino médio integrado; ensino técnico; ensino médio técnico; técnico integrado, entre outros. Para tal, utilizarei a nomenclatura Ensino Médio Integrado à Educação Profissional Técnica $(\text { EMIEPT })^{5}$, coadunando com a legislação vigente.

O Ensino Médio Integrado à Educação Profissional Técnica (EMIEPT) busca relacionar as partes do conhecimento, fracionado em disciplinas, à sua totalidade enquanto ciência, aproximando os conceitos e procedimentos que compõem o todo, visando à preparação dos educandos como cidadãos e para - exercício profissional qualificado. Dentro desta proposta integrada de formação, o currículo da formação geral e profissional pode ser articulado com a inclusão de temas que possibilitem o diálogo e a mediação entre os saberes.

Neste sentido, as Diretrizes Curriculares Nacionais para a Educação Ambiental (DCNEA) apresentam a inserção da Educação Ambiental (EA) como um tema que deve ser abordado em todos os níveis e fases escolares. Logo, a abordagem da temática ambiental na perspectiva da integração do currículo se apresenta como uma estratégia possível para a efetiva reunificação curricular de conhecimentos, permeando as fronteiras disciplinares e contribuindo para a formação integral e profissional do educando. Conforme prevê este trecho:

Art. 8o- A Educação Ambiental, respeitando a autonomia da dinâmica escolar e acadêmica, deve ser desenvolvida como uma prática educativa integrada e interdisciplinar, contínua e permanente em todas as fases, etapas, níveis e modalidades, não devendo, como regra, ser implantada como disciplina ou componente curricular específico (MEC, CNE/CP Resolução 2, 2012, p.3).

\footnotetext{
${ }^{3}$ Recorte da pesquisa de mestrado, desenvolvida no Mestrado Profissional em Educação e Tecnologia do Programa de Pós-Graduação em Educação do IFSUL, intitulada "A contribuição da Educação Ambiental para o Ensino Médio Integrado à Educação Profissional Técnica, defendida em 09/03/2018, encontra-se registrada no CEP/CONEP sob o número CAAE: 70655017.2.0000.8024.

4 Resolução nํ2, de 15 de junho de 2012. Estabelece as Diretrizes Curriculares Nacionais para a Educação Ambiental. Disponível em: <http://portal.mec.gov.br/index.php?option=com docman\&view= download\&alias=10988-rcp002-12-pdf\&category slug=maio-2012-pdf\&ltemid=30192>. Acesso: 01/06/18.

5 Embora a Resolução n 6/2012, que trata das Diretrizes Curriculares Nacionais para a Educação Profissional Técnica de Nível Médio (DCNEPTNM), consideramos, para este trabalho, o termo EMIEPT (Ensino Médio Integrado à Educação Profissional Técnica) para designar a Educação Profissional Técnica de Nível Médio na forma Articulada e Integrada ao Ensino Médio.
} 
As ações baseadas na Educação Ambiental são protagonistas das reflexões do indivíduo em torno de si e da sociedade em que estão inseridos. Podem mediar propostas integradoras ocupando as entrelinhas dos saberes, corroborando para a construção do pensamento crítico dos educandos, contribuindo para o desenvolvimento de indivíduos participativos no processo de ensino e aprendizagem. Portanto, a investigação sobre a percepção da Educação Ambiental pelos educandos do Curso Técnico em Vestuário, na forma de ensino integrado, contribuirá para a qualificação das práticas integradoras nesta modalidade de ensino. A percepção aqui citada é a concepção tomada de Merleau Ponty (2006), que sugere a construção da percepção a partir de perspectivas sobre o mesmo objeto. Ou seja, é a relação entre nós e este objeto, referindo-se a Educação Ambiental e as estudantes em formação profissional.

O artigo apresentado está dividido em quatro segmentos: a primeira parte traz aproximações entre a Educação Ambiental Crítica e Transformadora e a Educação Profissional Técnica (EPT), demonstrando a importância da inserção curricular da Educação Ambiental através das Diretrizes Curriculares Nacionais para a Educação Ambiental (DCNEA) e as potencialidades na construção de valores e atitudes dos educandos, na capacidade de transformar a si e a sociedade em que vivem. A segunda parte trata dos procedimentos metodológicos para a coleta de informações, enquanto a terceira e a quarta parte apresentam os resultados e as discussões emergidas da pesquisa e suas conclusões finais.

\section{Aproximações entre a Educação Ambiental e a Educação Profissional Técnica de nível médio}

O interesse em identificar as aproximações da Educação Ambiental (EA) com a Educação Profissional Técnica (EPT) no ensino médio integrado passa por compreender a maneira como as futuras Técnicas em Vestuário avaliam as questões ambientais do ponto de vista profissional. Perguntamo-nos se o currículo está contribuindo para esta tarefa, e assim, em um primeiro momento buscamos as aproximações possíveis entre a EA e a EPT.

Sabe-se que a Educação Ambiental - através da criação da Política Nacional de Educação Ambiental ${ }^{6}$ (1999) e das Diretrizes Curriculares Nacionais para a Educação Ambiental (2012) - emerge no campo educacional com grande potencial de articulação entre as áreas do conhecimento. Ao abordar a Educação Ambiental faz-se necessário, primeiramente, compreender qual Educação Ambiental está sustentando as práticas. Diversos autores adotam discursos distintos na intenção de classificá-la. Sauvé (2005) traça uma cartografia das correntes educativas em Educação Ambiental, ressaltando que

\footnotetext{
6 Política Nacional de Educação Ambiental, instituída pela Lei no 9.795, de 27 de abril de 1999 e regulamentada pelo Decreto no $\mathbf{4} .281$, de 25 de junho de 2002.
}

Revbea, São Paulo, V. 14, № 3: 307-324, 2019.

revista brasileira educação ambiental 
este quadro reagrupa teorias e práticas semelhantes, procurando diferenciá-las e aproximá-las em seus pontos comuns, divergentes e complementares.

Similarmente, Loureiro (2006) classificou a Educação Ambiental, didaticamente, em dois blocos. Assim como Sauvé (2005), reuniu as teorias ou categorias que guardavam em si aproximações nas concepções teórica e pedagógicas, tradicionalmente na educação e no campo político. Logo, dividiu a Educação Ambiental em dois grupos: o primeiro como conservador ou comportamentalista, com as seguintes particularidades:

Compreensão naturalista e conservacionista da crise ambiental; educação entendida em sua dimensão individual, baseada em vivências práticas; despolitização do fazer educativo ambiental, apoiando-se em pedagogias comportamentalistas ou alternativas de cunho místico; baixa problematização da realidade e pouca ênfase em processos históricos; foco na redução do consumo de bens naturais, descolando esta discussão do modo de produção que a define e situa; diluição da dimensão social na natural, faltando entendimento dialético da relação sociedade-natureza; responsabilização pela degradação posta em um homem genérico, fora da História, descontextualizado social e politicamente (LOUREIRO, 2006, p.133-134).

O segundo grupo foi denominado como transformador, crítico ou emancipatório, cujas características contemplam:

Busca da realização de autonomia e liberdades humanas em sociedade, redefinindo o modo como nos relacionamos com a nossa espécie, com as demais espécies e com o planeta; politização e publicização da problemática ambiental em sua complexidade; convicção de que a participação social e o exercício da cidadania são práticas indissociáveis da Educação Ambiental; preocupação concreta em estimular o debate e o diálogo entre ciências e cultura popular, redefinindo objetos de estudo e saberes; indissociação no entendimento de processos como: produção e consumo; ética, tecnologia e contexto sóciohistórico; interesses privados e interesses públicos; busca de ruptura e transformação dos valores e das práticas sociais contrários ao bem-estar público, à equidade e à solidariedade (LOUREIRO, 2006, p.133-134).

Considerando a divisão conceitual defendida por Loureiro (2006), esta pesquisa fundamentou-se na Educação Ambiental Crítica, definida "no âmbito do que chamamos de Educação Ambiental emancipatória, poderíamos incluir outras denominações como sinônimo ou concepções similares: Educação Ambiental crítica; Educação Ambiental popular; Educação Ambiental 
transformadora", ficando claro que não se trata de uma "Educação Ambiental genérica, de um conjunto de conceitos que servem indistintamente para qualquer atividade que se autodenomine como Educação Ambiental' (LOUREIRO, 2004, p. 33, grifo do autor). É importante destacar que os dispositivos legais que tratam da inclusão de temas referentes à Educação Ambiental no âmbito educativo referendam o enfoque crítico e transformador da Educação Ambiental, o que em concordância com Loureiro (2006) contribui para justificarmos nossa abordagem neste trabalho.

Neste caminho destacamos que as Diretrizes Curriculares Nacionais para a Educação Ambiental (DCNEA) apontam que a Educação Ambiental é um ente presente no cotidiano social e escolar dos indivíduos, conforme o trecho:

O atributo "ambiental" na tradição da Educação Ambiental brasileira e latino americana não é empregado para especificar um tipo de educação, mas se constitui em elemento estruturante que demarca um campo político de valores e práticas, mobilizando atores sociais comprometidos com a prática político-pedagógica transformadora e emancipatória capaz de promover a ética e a cidadania ambiental (BRASIL, Resolução CNE/CP № 2/2012, p.2, grifo da legislação).

Nesta direção a Educação Ambiental não se apresenta como um tipo especial de educação, mas como um elemento articulador e transformador de processos em que os indivíduos se mobilizam e constroem valores políticos, éticos e sociais, juntamente de conhecimentos, atitudes e habilidades que contribuem para além do entendimento do meio ambiente natural, direcionando-se para mudanças socioambientais.

Para tal, encontramos nas palavras de Loureiro (2004) embasamento referente à abordagem sobre a Educação Ambiental Crítica, que transforma e emancipa o sujeito ao anunciar que

A Educação Ambiental Transformadora enfatiza a educação enquanto processo permanente, cotidiano e coletivo pelo qual agimos e refletimos, transformando a realidade de vida. Está focada nas pedagogias problematizadoras do concreto vivido, no reconhecimento das diferentes necessidades, interesses e modos de relações na natureza que definem os grupos sociais e o "lugar" ocupado por estes em sociedade, como meio para se buscar novas sínteses que indiquem caminhos democráticos, sustentáveis e justos para todos. Baseia-se no princípio de que as certezas são relativas; na crítica e autocrítica constante e na ação política como forma de se estabelecer movimentos emancipatórios e de transformação social que possibilitem o estabelecimento de novos patamares de relações na natureza (LOUREIRO, 2004, p.81, grifo do autor). 
Através desta perspectiva, a Educação Ambiental proposta nas escolas reconhece os sujeitos do processo educativo, ou seja, educadores(as) e educandos(as) como indivíduos capazes de transformar a si e a sociedade em que estão inseridos, promovendo a reflexão de suas ações, "uma vez que conhecer, agir e se perceber no ambiente deixa de ser um ato teórico-cognitivo e torna-se um processo que se inicia nas impressões genéricas e intuitivas e que se tornando complexo e concreto na práxis"7 (LOUREIRO, 2006, p.148).

Garantindo espaço para a Educação Ambiental ser potencialmente transformadora, a Lei no 9.795/1999 apresenta a EA como elemento fundamental e permanente da educação, conforme:

Art. 2-- A Educação Ambiental é um componente essencial e permanente da educação nacional, devendo estar presente, de forma articulada, em todos os níveis e modalidades do processo educativo, em caráter formal e não formal (BRASIL, 1999, p.1).

$\mathrm{Na}$ educação formal, segundo o instrumento legal, a Educação Ambiental é apresentada como "uma prática educativa integrada, contínua e permanente em todos os níveis e modalidades do ensino formal'. Deste modo, estará em constante articulação com as disciplinas que compõem o currículo escolar, fortalecendo a sua propriedade interdisciplinar. O caráter interdisciplinar que a Educação Ambiental denota não sugere a criação de uma disciplina específica, porém, assegura a sua abordagem essencial e permanente de forma articulada em todos os níveis da educação formal, contemplando, assim, a educação profissional, em acordo com as legislações ${ }^{8}$.

A Educação Profissional com vistas à formação integral dos indivíduos, sob os diversos âmbitos, como o cultural, ambiental e intelectual, bem como a compreensão dos aspectos relacionados aos arranjos produtivos locais e do trabalho como um exercício complexo de hierarquia dos processos e não das pessoas, exige dos profissionais da educação uma reconfiguração do currículo. É importante destacar que a Educação Profissional sofreu uma reconfiguração com a criação dos Institutos Federais de Educação, Ciência e Tecnologia (IFs), através da Lei $\mathrm{n}^{\circ}$ 11.892/2008, e se organizaram a partir de instituições, como os CEFETs, escolas técnicas e agrotécnicas federais, e escolas vinculadas às universidades federais.

\footnotetext{
7 Entendida por Loureiro (2006, p. 149) como: "A práxis educativa transformadora é, portanto, aquela que fornece ao processo educativo as condições para a ação modificadora e simultânea dos indivíduos e dos grupos sociais; que trabalha a partir da realidade cotidiana visando à superação das relações de dominação e de exclusão que caracterizam e definem a sociedade capitalista globalizada". Disponível em: <http://www.scielo.br/pdf/es/v27n94/a07v27n94.pdf>. Acesso em 17 nov. 2017.

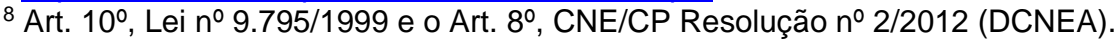


As Diretrizes Curriculares Nacionais para a Educação Profissional Técnica de Nível Médio (DCNEPTNM) definem as formas de oferta da Educação Profissional Técnica de Nível Médio:

Art. 7ํ A Educação Profissional Técnica de Nível Médio é desenvolvida nas formas articulada e subsequente ao Ensino Médio:

I - a articulada, por sua vez, é desenvolvida nas seguintes formas:

a) integrada, ofertada somente a quem já tenha concluído o Ensino Fundamental, com matrícula única na mesma instituição, de modo a conduzir o estudante à habilitação profissional técnica de nível médio ao mesmo tempo em que conclui a última etapa da Educação Básica;

b) concomitante, ofertada a quem ingressa no Ensino Médio ou já o esteja cursando, efetuando-se matrículas distintas para cada curso, aproveitando oportunidades educacionais disponíveis, seja em unidades de ensino da mesma instituição ou em distintas instituições de ensino; c) concomitante na forma, uma vez que é desenvolvida simultaneamente em distintas instituições educacionais, mas integrada no conteúdo, mediante a ação de convênio ou acordo de intercomplementaridade, para a execução de projeto pedagógico unificado;

II - a subsequente, desenvolvida em cursos destinados exclusivamente a quem já tenha concluído o Ensino Médio (BRASIL, 2012, p.3).

A Educação Profissional de Nível Técnico na forma integrada ou Ensino Médio Integrado à Educação Profissional Técnica (EMIEPT) parte da construção e formação unitária dos educandos através da integração das dimensões fundamentais da vida, tais como trabalho, ciência, tecnologia e cultura. Logo, proporcionar uma formação integral, que trata de superar a dualidade entre a cultura geral e a cultura técnica, é garantir esta integralidade através de uma educação que possibilite a formação dos educandos para o mundo do trabalho, no sentido amplo de participação social, política e cultural (FRIGOTTO, 2007). Portanto, a integração proposta no Ensino Médio Integrado à Educação Profissional Técnica (EMIEPT) procura relacionar a realidade social dos educandos com as áreas do conhecimento profissional e geral, divididos em disciplinas, promovendo a unificação dos conhecimentos e conferindo sentido de continuidade aos educandos.

A contribuição de um elemento mediador do conhecimento é fundamental para que haja êxito na integração curricular, na medida em que permeie as especificidades dos conteúdos das disciplinas, tecendo e entrelaçando a diversidade de fazeres e saberes das várias áreas do conhecimento que compõem o currículo escolar. Destacamos a Educação 
Ambiental como um componente de grande potencial, capaz de fazer esta articulação. Neste sentido, a Educação Ambiental Transformadora se mostra favorável a desempenhar este papel integrador, através de propostas que orientem o estudante a refletir sobre o espaço vivido, onde ele possa identificar e analisar a relação entre os elementos que compõe a vida e relacioná-los entre si.

Entretanto, a Lei de Diretrizes e Bases da Educação Nacional (LDB), no artigo 26으 $\S 7^{\circ}$, indicava a importância das discussões sobre Educação Ambiental na formação do educando enquanto sujeito em desenvolvimento. Porém, este artigo foi substituído pela redação dada na Lei oㅡ 13.415/20179, retirando a possibilidade da abordagem ambiental dos currículos, tolhendo sua abrangência.

Contrapondo a este retrocesso, cabe a possibilidade da inserção dos conhecimentos sobre a Educação Ambiental nos currículos, na forma de abordagens pedagógicas inter, multi e transdisciplinar ${ }^{10}$, com temas relacionados ao meio ambiente e a sustentabilidade socioambiental. Para a articulação destes temas, Leff (2010) aponta que é necessário estudo e reflexão para gerar mudanças, quando afirma que

[...] depreende-se a necessidade de estabelecer critérios e princípios para analisar a articulação destes processos. Também é preciso estudar os efeitos da problemática ambiental sobre as transformações metodológicas, as transferências conceituais e a circulação terminológica entre as diferentes disciplinas que participam na explicação e diagnóstico das transformações socioambientais, assim como a forma como estes paradigmas produzem e assimilam um conceito de meio ou de ambiente. Do estudo destas mudanças epistêmicas surge a possibilidade de produzir conceitos práticos para orientar uma transformação produtiva fundada nos princípios da gestão ambiental do desenvolvimento e do manejo sustentável dos recursos (LEFF, 2010, p.70).

O autor também reforça a preocupação em rever as metodologias utilizadas e o compartilhamento de conceitos e terminologias da área ambiental para o efetivo diálogo e integração das diferentes disciplinas que partilham do

\footnotetext{
${ }^{9}$ A LDB/96 previa, no artigo $26^{\circ}$, $\S 7^{\circ}$, que "os currículos do ensino fundamental e médio devem incluir os princípios da proteção e defesa civil e a Educação Ambiental de forma integrada aos conteúdos obrigatórios", alterando o referido artigo para a seguinte redação: "a integralização curricular poderá incluir, a critério dos sistemas de ensino, projetos e pesquisas envolvendo os temas transversais de que trata o caput". Disponível em: <http://www.planalto.gov.br/ccivil 03/ Ato2015-2018/2017/Lei/L13415.htm>. Acesso em: 16 mar. 2018.

10 Esses conceitos podem ser estudados em: PHILIPPI JR.; TUCCI; HOGAN; NAVEGANTES. Interdisciplinaridade em Ciências Ambientais. São Paulo: Signus Editora. p. 54-59, 2000. Disponível em: $<$ http://www.dominiopublico.gov.br/download/texto/us000001.pdf>. Acesso em: 1 ago. 2016.
} 
processo de Educação Ambiental. Para tanto, faz-se necessário uma reorientação na prática docente no sentido de este profissional tornar-se, também, reflexivo (SCHÖN, 1992). Isto é, olhar para os respectivos contextos de maneira em que consigam pensar os conceitos que orientam o seu trabalho, partindo do lugar de onde estão e, assim, reorientando suas práticas, pois, para que a Educação Ambiental seja transformadora e emancipatória ${ }^{11}$ para o educando, não é desejável que isto exista apenas no texto legal, mas sim, algo do qual o sujeito se sinta parte e responsável por todo o processo.

Loureiro (2007) destaca a seriedade desse entendimento:

Assim, a questão não é somente conhecer para se ter consciência de algo, mas conhecer inserido no mundo para que se tenha consciência crítica do conjunto de relações que condicionam certas práticas culturais e, nesse movimento, superarmo-nos e às próprias condições inicialmente configuradas (LOUREIRO, 2007, p.69).

$\mathrm{Na}$ Educação Profissional é importante que os educandos do EMIEPT tenham conhecimento da legislação ambiental pertinentes às funções técnicas, reforçando a responsabilidade social e ambiental como futuros profissionais. Contudo, apenas a informação dos regramentos legais não possui o poder de modificar atitudes, visto que "somente quando se compreende a importância do que ela tutela ou disciplina, captando seu sentido educativo, é que ela pode ser transformadora de valores, atitudes e das relações sociais" (LIPAl; LAYRARGUES; PEDRO, 2007, p.31). Neste sentido, Loureiro (2004, p.35) retoma o comprometimento da Educação Ambiental Crítica e Transformadora para a vida e formação dos educandos quando menciona

[...] que a Educação Ambiental crítica, transformadora, socioambiental e popular se refere, enquanto práxis social e processo de reflexão sobre a vida e a natureza, contribuindo com a transformação do modo como nos inserimos e existimos no mundo, a uma única categoria teórico-prática estruturante: educação.

Desta feita pode-se constatar que, ao ser entendida como processo, a Educação Ambiental Transformadora envolve o percurso de vida do indivíduo, sendo de grande importância na formação e emancipação do sujeito como articulador e transformador da sociedade, envolvendo diversas áreas do conhecimento e fazendo parte do seu percurso de vida enquanto educando e

11 Conceito utilizado na perspectiva encontrada em Loureiro (2005). Disponível em: $<$ http://www.scielo.br/pdf/es/v26n93/27289.pdf>. Acesso em 13 jan. 2017.

revista brasileira educação ambiental 
cidadão. As ações baseadas na Educação Ambiental Crítica e Transformadora são protagonistas das reflexões do indivíduo em torno de si e da sociedade em que estão inseridos, e podem mediar propostas integradoras ocupando as entrelinhas dos saberes, corroborando para a construção do pensamento crítico dos educandos e tornando-os indivíduos participativos no processo de ensino e aprendizagem.

A construção de passagens no currículo, que alcancem a integração favorecidas pela Educação Ambiental Transformadora, conduz à reflexão das diversas áreas do conhecimento, com o intuito de desfazer contornos mais endurecidos da ciência e reorganizar os conhecimentos fracionados, buscando a unificação dos saberes. Logo, uma abordagem curricular que prime pelas práticas educativas integradoras dos conhecimentos, tendo a Educação Ambiental como um elemento mobilizador dos sujeitos sociais, comprometidos na transformação da sua realidade e da sociedade, atenderia aos diversos dispositivos legais e socioambientais. Desta forma, ressalto que este é o nosso objetivo e o que buscamos identificar com esta pesquisa, saber se o Curso Técnico em Vestuário está caminhando nesta direção, sob a finalidade de contribuir com a formação dos profissionais que passam pelo seu currículo.

\section{Trajetória metodológica}

Para analisarmos a percepção dos estudantes em relação à Educação Ambiental, no currículo do curso Técnico em Vestuário do IFSUL/CaVG, optamos por uma pesquisa de cunho qualitativo, do tipo estudo de caso. Entendendo que esta metodologia favorece o estudo das possíveis intervenções da vida real, propiciando a avaliação e a análise dos resultados das situações do estudo (YIN, 2010). Além disso, a pesquisa qualitativa favorece a compreensão das questões sociais no âmbito escolar, a partir do contato com as pessoas que estão vivendo sob o fenômeno pesquisado, neste caso, a transversalidade da Educação Ambiental na formação profissional.

Além do contato com os indivíduos que compõe o seleto grupo de formandas, os documentos referentes ao curso e a própria instituição constituíram parte da pesquisa, pois foi uma forma de estabelecermos as relações entre o currículo do Curso Técnico em Vestuário que recebem estas estudantes em processo de formação. Para isso, utilizamos como dispositivo de coleta de dados um questionário misto, contendo perguntas fechadas e abertas, desenvolvido com o intuito de explicar a percepção que as formandas possuem sobre a Educação Ambiental. Por intermédio do cruzamento das informações obtidas no contato com as educandas e os documentos analisados, buscamos correlacionar os dados para a análise, validando, portanto, esta pesquisa. 
O estudo foi desenvolvido com as formandas ${ }^{12}$ do Curso Técnico em Vestuário do IFSUL - campus Pelotas - Visconde da Graça (CaVG), na forma de ensino integrado, composta por oito educandas. A pesquisa tinha como objetivo investigar a percepção destas educandas sobre a Educação Ambiental abordada em seu percurso formativo. A pesquisa seguiu as recomendações referentes à ética na pesquisa, conforme a Resolução no 466/12 e a Resolução ํo 510/2016, ambas expedidas pelo Conselho Nacional de Saúde. A escolha por este curso se deve à atuação de uma das autoras como docente no mesmo.

\section{Resultados e discussão}

Considerando a relevância dos aspectos educativos ambientais na formação dos profissionais, especialmente no campo da formação profissional técnica, dispomo-nos a verificar se o currículo abarca esta temática, segundo a percepção das estudantes do curso integrado em Vestuário. As informações emergidas do questionário foram analisadas e interpretadas, a fim de buscar aproximações e distanciamentos referentes à percepção das educandas quanto à abordagem da Educação Ambiental Crítica e Transformadora no Ensino Médio Integrado e a Educação Profissional Técnica (EMIEPT) do curso Técnico em Vestuário do IFSUL/CaVG.

O grupo pesquisado é composto pela turma de formandas/2017, entendendo que elas já percorreram todas as etapas formativas do curso, logo, são capazes de contribuir com relatos de suas vivências no decorrer da sua formação. No momento da tomada de informações estavam presentes somente oito (8) de um total de onze (11) educandas, que fizeram parte do coletivo da pesquisa. Para o tratamento das informações foram analisados e identificados fragmentos das respostas escritas pelas interlocutoras no formulário de pesquisa, e organizados em grupos de significados que foram tabulados para auxiliar na compreensão e discussão dos elementos coletados, conforme as tabelas a seguir.

A primeira questão - "O que entendes por Educação Ambiental?" -, demonstra o entendimento das educandas sobre a Educação Ambiental, na qual surgiu a seguinte informação (Tabela 1):

Tabela 1: Entendimento das educandas sobre a Educação Ambiental.

\begin{tabular}{|c|c|}
\hline \multicolumn{2}{|c|}{ Entendimento das educandas sobre a Educação Ambiental } \\
\hline & $\begin{array}{l}\text { Informações das } \\
\text { interlocutoras }\end{array}$ \\
\hline Postura conservadora ou comportamentalista & 08 \\
\hline Postura crítica, transformadora ou emancipatória & 00 \\
\hline TOTAL DE INTERLOCUTORAS & 08 \\
\hline \multicolumn{2}{|c|}{ Fonte: Autoria própria. } \\
\hline
\end{tabular}

Revbea, São Paulo, V. 14, № 3: 307-324, 2019.

revista brasileira 
Para a interpretação destas informações consideramos a classificação dada à Educação Ambiental por Loureiro (2006), por entender que estas características correspondem às percepções das educandas. $O$ autor, que divide a Educação Ambiental em dois grupos: a Educação Ambiental conservadora ou comportamentalista no primeiro grupo, cujas bases centrais se apoiam na "compreensão naturalista e conservacionista da crise ambiental; foco na redução do consumo de bens naturais, descolando esta discussão do modo de produção que a define e situa [...]". O segundo grupo foi denominado de transformador, crítico ou emancipatório, classificado pela semelhança de concepções, tais como a "busca da realização de autonomia e liberdades humanas em sociedade, redefinindo o modo como nos relacionamos com a nossa espécie, com as demais espécies e com o planeta; convicção de que a participação social e o exercício da cidadania são práticas indissociáveis da Educação Ambiental [...]" (LOUREIRO, 2006, p.133-134).

Seguindo a classificação do autor, fica evidenciado ao observar a tabela que a Educação Ambiental de cunho conservador predomina na compreensão trazida pelas educandas, acumulada por muitos anos de formação escolar. Possivelmente, o currículo no qual houve a formação até o momento da pesquisa não abordou, ou não foi compreendida, como Educação Ambiental Crítica. Os dados revelam que, para a totalidade da turma, a Educação Ambiental significa o estudo do meio ambiente, da água, da degradação, do cuidado com o meio ambiente natural, sendo confirmado pela seguinte resposta: "É um processo que é criado para formar indivíduos preocupados com os problemas ambientais. Ou seja, pessoas que se importam com poluição, desmatamento etc." (Educanda 2).

O trecho transmite o desconhecimento, por parte de algumas educandas, dos propósitos da abordagem ambiental para a sua formação enquanto indivíduo, e também como futuros profissionais. A compreensão naturalista da Educação Ambiental por parte dos educadores e educadoras, destacada pelas educandas, evidencia traços da formação equivocada recebida em tratar a Educação Ambiental como uma questão ligada à reciclagem de resíduos, de poluição das águas, etc., apontados como temas ligados a algumas disciplinas e não a outras (DEORCE, 2013; RODRIGUES, 2012).

Guimarães (2013) propõem uma justificativa desta conduta simplista de alguns educadores(as), da tendência de, ao trabalharem com a Educação Ambiental, partirem de práticas reconhecidas pela sociedade, mesmo procurando realizar algo diferente. A este movimento o autor chama de armadilha paradigmática, como melhor explica no recorte do texto:

É a essa dinâmica que estou chamando de armadilha paradigmática, quando o educador, por estar atrelado a uma visão (paradigmática) fragmentária, simplista e reduzida da realidade, manifesta (inconscientemente) uma compreensão limitada da problemática ambiental e que se expressa por uma 
incapacidade discursiva, que cria amarras para 0 desenvolvimento de uma visão crítica e complexa do real, refletindo em uma prática pedagógica fragilizada de Educação Ambiental, [...]. Essa prática pedagógica presa à armadilha paradigmática não se apresenta apta a fazer diferente e tende a reproduzir as concepções tradicionais do processo educativo, baseadas nos paradigmas da sociedade moderna, sendo esse um poderoso mecanismo de alienação ideológica e de manutenção da hegemonia (GUIMARÃES, 2013, p.21).

Para o autor, quando os educadores(as) agem assim estão pensando da mesma maneira tradicional, reproduzindo modelos vinculados às concepções conservadoras e reduzidas da Educação Ambiental, impedindo ou dificultando a atuação crítica e problematizadora inerentes à Educação Ambiental. Outro enfoque dado pela pesquisa evidencia a percepção das educandas sobre a temática ambiental abordada nas disciplinas, apontadas na tabela abaixo:

Tabela 2: Entendimento das educandas sobre a abordagem nas disciplinas de questões ambientais ao longo do Curso Técnico em Vestuário.

\begin{tabular}{l|c|c}
\hline \multicolumn{3}{c}{ Entendimento das educandas sobre a abordagem de questões ambientais } \\
\hline & $\begin{array}{c}\text { Número de vezes } \\
\text { apontadas pelas } \\
\text { interlocutoras }\end{array}$ & Percentual (\%) \\
\hline Biologia & 06 & $42,86 \%$ \\
\hline Geografia & 04 & $28,57 \%$ \\
\hline Sociologia & 01 & $7,14 \%$ \\
\hline Filosofia & 01 & $7,14 \%$ \\
\hline Projeto de Confecção & 01 & $7,14 \%$ \\
\hline Tecnologia Têxtil & 01 & $7,14 \%$ \\
\hline TOTAL & 14 & $100 \%$ \\
\hline
\end{tabular}

Fonte: Autoria própria.

Em relação às disciplinas que mais abordaram temas referentes à Educação Ambiental durante o percurso formativo, Biologia e Geografia foram apontadas pelas educandas como as disciplinas que, comumente, são responsabilizadas pela abordagem ambiental nas escolas, pois estudam as relações dos seres humanos com a natureza. Todas as educandas concordaram com a presença da temática ambiental em outras disciplinas.

Segundo Kuss et al. (2015), estas distorções derivam da concepção inicial de Educação Ambiental praticada no Brasil. Ou seja, a forma conservacionista e comportamental que, compreendia a Educação Ambiental apenas como o meio ambiente e a natureza. Do ponto de vista da aproximação da Biologia e da Geografia com a Educação Ambiental, passa pela própria epistemologia dessas ciências que trazem em seu cerne a compreensão do espaço. O próprio docente ao investigar, analisar e identificar os aspectos contraditórios aponta a relação da sociedade e da natureza como responsável 
pelas análises mais superficiais, sobretudo ao que está relacionado ao lixo, desmatamento e contaminação da água e do ar.

Uma avaliação mais aprofundada sobre este aspecto pode ser lida em Calixto e Santos (2012; 2013), um estudo sobre a abordagem educativa ambiental pelos professores de educação básica na cidade de Piratini, interior do Rio Grande do Sul. Concluiu-se que a formação inicial de professores, bem como a ausência de formação continuada para professores em serviço, contribui para uma abordagem equivocada da Educação Ambiental no currículo. Percebeu-se que os docentes, por não terem em suas formações orientações e aprofundamento sobre o que é o currículo e como se faz a introdução de um tema transversal, não o fazem de modo adequado. Por isso defendemos a formação continuada em serviço para favorecer as condições de aplicação da Educação Ambiental no currículo.

Portanto, este trabalho trouxe à superfície uma realidade da qual a maioria das escolas brasileiras faz parte. A instituição IFSUL/CaVG não é uma exceção ao não fazer abordagem da Educação Ambiental Transformadora, como compreendemos que seria ideal na formação de nossos estudantes.

Os resultados revelaram que não apenas a abordagem ambiental precisa ser cuidadosamente pensada para a inclusão no currículo, mas também a concepção de trabalhador que este currículo traz. Embora haja o entendimento de que esta discussão adéqua-se para um trabalho futuro, consideramos que, na prática, ao não termos um currículo integrado e uma cisão fortemente marcada entre as disciplinas técnicas e as disciplinas de formação geral, e uma abordagem ambiental alinhada a duas disciplinas (Geografia e Biologia), na prática, estamos reforçando que aqueles que não possuem relação direta com estas ciências não são responsáveis pela garantia de um ambiente saudável, equilibrado e justo.

Nós, professores atuantes no Ensino Médio Integrado, precisamos nos debruçar sobre o currículo integrado e pensar de forma objetiva e prática em como levaremos esta perspectiva para além das discussões teóricas. Ainda que, atualmente, estejamos passando por momentos delicados de âmbito político e com reflexões severas na educação profissional, sobretudo em relação ao currículo integrado. Ainda assim, destacamos a importância do seu caráter formador humano, no qual o estudante poderá optar, no futuro, por fazer o que desejar diante de um mundo de trabalho complexo.

\section{Considerações finais}

O presente artigo, como recorte de uma pesquisa de maior proporção sobre a abordagem ambiental e a Educação Profissional e Técnica, contribui para que seja possível repensar o currículo integrado e o papel do tema transversal Educação Ambiental na formação dos profissionais da área do vestuário. Tímidos avanços foram percebidos nas discussões sobre a Educação Ambiental no âmbito escolar do Ensino Médio Integrado à Educação 
Profissional, na direção de modificações substanciais e horizontalizadas, voltadas para o estudo da responsabilidade, tanto individual como coletiva para com o meio ambiente natural e social.

Os textos legais permaneceram pouco explorados nestes vinte anos da criação da Política Nacional de Educação Ambiental (PNEA) e nos sete anos das DCNEA, no que tange as discussões nos Institutos Federais sobre a compreensão da dimensão ambiental na formação humana, permanecendo no âmbito do atendimento legal à abordagem da Educação Ambiental no organismo escolar.

Tal fato se confirma nos resultados apresentados através desta pesquisa, que investigou a percepção das educandas do curso Técnico em Vestuário do IFSUL/CaVG sobre a abordagem da Educação Ambiental. O estudo revelou o predomínio da postura conservadora e comportamentalista da Educação Ambiental, tanto nas abordagens dos educadores(as) em sala de aula, como na compreensão que as educandas possuem sobre a Educação Ambiental, limitando-se ao estudo e a preocupação com o meio ambiente natural, em detrimento ao enfoque crítico e transformador, propostos na legislação.

A dominação da visão conservacionista e comportamental pode ser atribuída ao início dos estudos sobre Educação Ambiental no Brasil que, embrionariamente, buscaram na natureza aproximação e afinidade para o ingresso e as discussões do tema na sociedade. As informações levantadas na pesquisa corroboram com esta tendência, apontando as áreas de Biologia e Geografia como as disciplinas que mais estabeleceram diálogo com a Educação Ambiental. Atribui-se, em parte, aos centros de formação de educadores(as) a prevalência desta visão comportamentalista e conservadora da Educação Ambiental, uma vez que não contemplam a Educação Ambiental na sua visão crítica e transformadora em seus currículos, comprometendo, desse modo, a inserção de enfoque crítico nas práticas educativas cotidianas, coibindo a promoção da autonomia dos pensamentos e atitudes, e incidindo diretamente na formação dos jovens educandos.

Como pesquisadoras da Educação Profissional, acreditamos na urgência referente ao tratamento e às questões da presença da Educação Ambiental nos currículos dos cursos integrados, para que seja de uma maneira satisfatória, na qual haja educadores e educadoras com conhecimento na área. Para tanto, indicamos a formação continuada como um espaço importante para esta apresentação, pois sabemos que muitos docentes não possuem abordagens ambientais teóricas em suas formações iniciais. 


\section{Referências}

BRASIL. Lei no 9.394, de 20 de dezembro de 1996. Estabelece as diretrizes e bases da educação nacional. Coordenação de Edições Técnicas, 2017. Disponível em: <https://www2.senado.leg.br/bdsf/bitstream/handle/id/529732/ lei de diretrizes e bases 1ed.pdf >. Acesso em 21 mar. 2018.

BRASIL. Lei no 9.795, de 27 de abril de 1999. Dispõe sobre a Educação Ambiental, institui a Política Nacional de Educação Ambiental e dá outras providências. Disponível em: <http://www.planalto.gov.br/ccivil 03/Leis/ L9795.htm>. Acesso em: 27 maio 2016.

BRASIL. Lei no 11.892 de 29 de dezembro de 2008. Institui a Rede Federal de Educação Profissional, Científica e Tecnológica, cria os Institutos Federais de Educação, Ciência e Tecnologia, e dá outras providências. Brasília, 2008. Disponível em: <http://www.planalto.gov.br/ccivil 03/ ato2007-2010/2008/lei/ 111892.htm>. Acesso em: 30 jun. 2018.

BRASIL. Lei no 13.415, de 16 de fevereiro de 2017. Altera as Leis nos 9.394, de 20 de dezembro de 1996, que estabelece as diretrizes e bases da educação nacional, e 11.494, de 20 de junho 2007, que regulamenta o Fundo de Manutenção e Desenvolvimento da Educação Básica e de Valorização dos Profissionais da Educação, a Consolidação das Leis do Trabalho - CLT, aprovada pelo Decreto-Lei no 5.452, de 1 de maio de 1943, e o Decreto-Lei no 236, de 28 de fevereiro de 1967; revoga a Lei o 11.161, de 5 de agosto de 2005; e institui a Política de Fomento à Implementação de Escolas de Ensino Médio em Tempo Integral. Disponível em: <http://www.planalto.gov.br/ccivil 03/ ato2015-2018/2017/lei/l13415.htm >. Acesso em: 6 mar. 2017.

BRASIL. Decreto no 4.281, de 25 de junho de 2002. Regulamenta a Lei no 9.795, de 27 de abril de 1999, que institui a Política Nacional de Educação Ambiental, e dá outras providências. Disponível em: <http://www.planalto.gov. br/ccivil 03/decreto/2002/d4281.htm>. Acesso em: 22 mar. 2018.

BRASIL. MEC. CNE. CEB. Resolução no 6, de 20 de setembro de 2012. Define Diretrizes Curriculares Nacionais para a Educação Profissional Técnica de Nível Médio. Disponível em: <http://portal.mec.gov.br/index.php?option= com docman\&view=download\&alias=11663-rceb006-12-pdf\&category slug= setembro-2012-pdf\&ltemid=30192>. Acesso em: 27 maio 2017.

BRASIL. MEC. CNE. CP. Resolução no 2, de 15 de junho de 2012. Estabelece as Diretrizes Curriculares Nacionais para a Educação Ambiental. Disponível em: <http://portal.mec.gov.br/index.php?option=com docman\&view= download\&alias=10988-rcp002-12-pdf\&category slug=maio-2012pdf\&ltemid=30192>. Acesso em: 1 jun. 2016.

BRASIL. MEC. CNE. Base Nacional Comum Curricular - Ensino Médio. Disponível em: <http://portal.mec.gov.br/conselho-nacional-de-educacao/basenacional-comum-curricular-bncc-etapa-ensino-medio >. Acesso em: 15 nov. 2018. 
BRASIL. MS. CNS. Resolução 466, de 12 de dezembro de 2012. Aprovar as diretrizes e normas regulamentadoras de pesquisas envolvendo seres humanos. Disponível em: <http://conselho.saude.gov.br/resolucoes/ 2012/reso466.pdf>. Acesso em: 4 nov. 2017.

BRASIL. MS. CNS. Resolução 510, de 7 de abril de 2016. Dispõe sobre as normas aplicáveis a pesquisas em Ciências Humanas e Sociais cujos procedimentos metodológicos envolvam a utilização de dados diretamente obtidos com os participantes ou de informações identificáveis ou que possam acarretar riscos maiores do que os existentes na vida cotidiana, na forma definida nesta Resolução. Disponível em: <http://conselho.saude. gov.br/resolucoes/2016/Reso510.pdf>. Acesso em: 4 nov. 2017.

CALIXTO, P.M.; SANTOS, A.C.K. Possibilidades de articulação entre a geografia escolar e a Educação Ambiental a partir do uso de um atlas escolar. Geografia. v. 21, n. 3, p. 57-73, 2012.

CALIXTO, P.M.; SANTOS, A.C.K. Contribuições para ressignificação da prática da Educação Ambiental pelos professores de geografia. RA'eGA. v. 28, p. 254278, 2013.

DEORCE, M.S. Caminhos para uma Educação Ambiental crítica como centro de forças no currículo do curso técnico em Mecânica do IFES/câmpus Vitória. 2013, 130f. Tese. (Programa de Pós-Graduação em Educação: Currículo da Pontifica Universidade Católica de São Paulo), São Paulo, 2013.

FRIGOTTO, G. A relação da Educação Profissional e tecnológica com a universalização da Educação Básica. Educação \& Sociedade. Campinas, v. 28, n. 100 (Especial), p. 1129-1152, out. 2007.

GUIMARÃES, M. Por uma Educação Ambiental crítica na sociedade atual . Revista Margens Interdisciplinar. v. 7, n. 9, p. 11-22. 2013.

KUSS, A.V. (Org.). et all. Possibilidades metodológicas para a pesquisa em Educação Ambiental. Pelotas: Editora e Cópias Santa Cruz, 2015. Disponível em: $\quad<$ https://wp.ufpel.edu.br/educambiental/files/2017/05/PossibilidadesMetodologicas-da-pesquisa-em-educacao-ambiental.pdf>. Acesso em: 25 nov. 2017.

LEFF, E. Epistemologia ambiental. 5ª ed. São Paulo: Cortez, 2010.

LIPAI, E.M.; LAYRARGUES, P.P.; PEDRO, V.V. Educação Ambiental na escola: tá na lei.... In: MELLO, S.S.; TRAJBER, R. (Coord.). Vamos cuidar do Brasil: conceitos e práticas em Educação Ambiental na escola. Ministério da Educação. Coordenação Geral de Educação Ambiental. Ministério do Meio Ambiente. Departamento de Educação Ambiental. Brasília: UNESCO, p. 23-32. 2007. Disponível em: <http://portal.mec.gov.br/dmdocuments/publicacao3.pdf>. Acesso em 10 jul. 2016.

LOUREIRO, C.F.B. Trajetória e fundamentos da Educação Ambiental. São Paulo: Cortez, 2004. 
LOUREIRO, C.F.B. Educação Ambiental Transformadora. In: LAYRARGUES, Philippe Pomier (Org.). Identidades da Educação Ambiental brasileira. Brasília: MMA. p. 65-84, 2004. Disponível em: <https://www.mma.gov.br/ estruturas/educamb/ arquivos/livro ieab.pdf>. Acesso em Acesso em 10 jul. 2016.

LOUREIRO, C.F.B. Complexidade e dialética: contribuições à práxis política e emancipatória em Educação Ambiental. Educação e Sociedade. Campinas. v. 27, n. 94, p. 131-152, jan.-abr. 2006. Disponível em: <http://www.scielo.br /pdf/es/v27n94/a07v27n94.pdf>. Acesso em 17 nov. 2017.

LOUREIRO, C.F.B. Educação Ambiental crítica: contribuições e desafios. In: MELLO, S.S.; TRAJBER, R. (Coord.). Vamos cuidar do Brasil: conceitos e práticas em Educação Ambiental na escola. Ministério da Educação, Coordenação Geral de Educação Ambiental. Ministério do Meio Ambiente, Departamento de Educação Ambiental. Brasília: UNESCO. p. 65-71. 2007. Disponível em: <http://portal.mec.gov.br/dmdocuments/publicacao3.pdf>. Acesso em 10 jul. 2016.

MERLEAU-PONTY, M. Fenomenologia da percepção. $3^{\text {a }}$ ed. SP: Martins Fontes, 2006.

PHILIPPI JR, A.; TUCCI, C.E. M.; HOGAN, D.J.; NAVEGANTES, R. Interdisciplinaridade em Ciências Ambientais. São Paulo: Signus Editora. p. 54-59, 2000. Disponível em: <http://www.dominiopublico.gov.br/ download/texto/us000001.pdf >. Acesso em: 1 ago. 2016.

RODRIGUES, H.L. Educação Ambiental no ensino médio: o que pensam e o que dizem os professores. 2012,128f. Dissertação. (Programa de PósGraduação em Educação da Universidade Federal do Maranhão) São Luís, 2012.

SAUVÉ, L. Uma cartografia das correntes em Educação Ambiental. In: SATO, M.; CARVALHO, I. (Org.). Educação Ambiental: pesquisa e desafios. Porto Alegre: Artmed, p.17-45. 2005.

SCHÖN, D.A. Formar professores como profissionais reflexivos. In: NÓVOA, A. (Coord.). Os professores e sua formação. Lisboa: Dom Quixote, 1992.

YIN, R.K. Estudo de Caso: planejamento e métodos. 4 ed. Porto Alegre: Bookman, 2010.

ZITZKE. V.A. A contribuição da Educação Ambiental para o ensino médio integrado à educação profissional técnica. 2018. 218 f. Dissertação. (Programa de Pós-Graduação em Educação). Instituto Federal de Educação, Ciência e Tecnologia Sul-rio-grandense, Pelotas, 2018. Disponível em: $<$ http://biblioteca.ifsul.edu.br/pergamum/anexos sql hom81/000036/000036d1. pdf>. Acesso em: 23 jan. 2019. 